\title{
Heat and risk of myocardial infarction: hourly level case-crossover analysis of MINAP database
}

\author{
(c) $\underset{1}{(1)(8)}$ OP DeN ACCESS
}

\author{
Krishnan Bhaskaran lecturer in statistical epidemiology ${ }^{1}$, Ben Armstrong professor of epidemiological \\ statistics $^{2}$, Shakoor Hajat senior lecturer in epidemiology and medical statistics ${ }^{2}$, Andy Haines \\ professor of public health and primary care ${ }^{2}$, Paul Wilkinson professor of environmental \\ epidemiology ${ }^{2}$, Liam Smeeth professor of clinical epidemiology ${ }^{1}$
}

${ }^{1}$ Department of Non-communicable Diseases Epidemiology, London School of Hygiene and Tropical Medicine, London WC1E 7HT, UK; ${ }^{2}$ Department of Social and Environmental Health Research, London School of Hygiene and Tropical Medicine, London, UK

\begin{abstract}
Objective To quantify the association between exposure to higher temperatures and the risk of myocardial infarction at an hourly temporal resolution.

Design Case-crossover study.

Setting England and Wales Myocardial Ischaemia National Audit Project (MINAP) database.

Participants 24861 hospital admissions for myocardial infarction occurring in 11 conurbations during the warmest months (June to August) of the years 2003-09.
\end{abstract}

Main outcome measure Odds ratio of myocardial infarction for a $1^{\circ} \mathrm{C}$ increase in temperature.

Results Strong evidence was found for an effect of heat acting 1-6 hours after exposure to temperatures above an estimated threshold of $20^{\circ} \mathrm{C}$ $\left(95 \%\right.$ confidence interval $16^{\circ} \mathrm{C}$ to $\left.25^{\circ} \mathrm{C}\right)$. For each $1^{\circ} \mathrm{C}$ increase in temperature above this threshold, the risk of myocardial infarction increased by $1.9 \%(0.5 \%$ to $3.3 \%, P=0.009)$. Later reductions in risk seemed to offset early increases in risk: the cumulative effect of a $1^{\circ} \mathrm{C}$ rise in temperature above the threshold was $0.2 \%(-2.1 \%$ to $2.5 \%)$ by the end of the third day after exposure.

Conclusions Higher ambient temperatures above a threshold of $20^{\circ} \mathrm{C}$ seem to be associated with a transiently increased risk of myocardial infarction 1-6 hours after exposure. Reductions in risk at longer lags are consistent with heat triggering myocardial infarctions early in highly vulnerable people who would otherwise have had a myocardial infarction some time later ("short term displacement"). Policies aimed at reducing the health effects of hot weather should include consideration of effects operating at sub-daily timescales.

\section{Introduction}

In the light of global climate change, interest in the effects of meteorological factors on human health outcomes is increasing. Several studies have shown high outdoor ambient temperature to be associated with increased overall mortality in the short term, ${ }^{1-5}$ but the effect of high temperatures on the risk of myocardial infarction specifically is less clear.

In a recent systematic review, just over half (7/13) of the studies with relevant data reported a statistically significant association between higher temperatures and risk of myocardial infarction, but several studies prompted concerns about the specificity of the outcome owing to the lack of separate validation and the potential for inclusion of events not related to myocardial infarction. ${ }^{6}$ In a time series analysis based on UK data, we observed increases in the risk of myocardial infarction at colder but not at warmer ambient temperatures. ${ }^{7}$ However, this and other studies to date have examined temperature-myocardial infarction associations at a daily temporal resolution and may thus have missed heat effects operating on a sub-daily timescale. Associations between heat and mortality outcomes have been shown to operate with relatively little delay, in contrast to the effects of cold. ${ }^{8}$ Furthermore, effects of other environmental factors, in particular air pollution, on myocardial ischaemia and risk of myocardial infarction have been observed within just a few hours of exposure. ${ }^{910}$

We therefore aimed to quantify the association between exposure to higher temperatures and the risk of myocardial infarction at an hourly temporal resolution, using environmental data linked to a large database of myocardial infarction events in England and Wales that records time of event data, and within which the 
validity of events could be confirmed against data on electrocardiographic and laboratory markers.

\section{Methods}

The web appendix gives more detail of the methods.

\section{Clinical data and events included}

The Myocardial Ischaemia National Audit Project (MINAP) is a national register that records all hospital admissions for myocardial infarction and other acute coronary syndromes, with participation from all hospitals in England and Wales that admit patients with these conditions (details in web appendix). We included all events with a discharge diagnosis of ST elevation myocardial infarction, non-ST elevation myocardial infarction, or troponin positive acute coronary syndrome and with the time of the event available occurring among patients residing in one of 11 large conurbations in England and Wales (Greater London, West Midlands, Greater Manchester, West Yorkshire, Tyneside, Liverpool, Nottingham, Sheffield, Bristol, Potteries, and Cardiff, with conurbation boundaries pre-defined to match earlier work $\left.^{11}\right)$. We used data covering the years 2003-09, and to investigate effects of heat specifically we restricted our analysis to the warmest quarter of the year-namely, June to August (the warmest three consecutive months in $69 \%$ of conurbation years). Timing data may be recorded in MINAP at several points during the course of an event. When it was directly recorded, we used the time of onset of symptoms as the time of the event. When this was not available, we used one of the following time fields (in order of preference): first call for help, arrival of first professional, arrival of emergency services, arrival at hospital, reperfusion, or cardiac arrest. Where we used time fields other than time of onset of symptoms, we adjusted them by the median difference between symptom onset and the timing variable in question, to generate the estimated time of symptom onset for all patients; for example, if we used time of arrival at hospital, we subtracted the median difference between time of symptom onset and time of arrival at hospital for the study population.

\section{Data on temperature and potential confounders}

For each of the 11 conurbations, we obtained hourly temperature and relative humidity data from weather monitoring stations within the conurbation from the British Atmospheric Data Centre (UK Meteorological Office MIDAS land surface stations data ${ }^{12}$ ). We also obtained hourly ambient levels of the following pollutants: nitrogen dioxide, particulate matter with diameter $<10 \mu \mathrm{m}$, and ozone. Pollutant data originated from urban background monitoring stations within each conurbation, and we retrieved them from the UK Air Quality Data and Statistics Database. ${ }^{13}$

\section{Statistical analysis}

We did a fixed stratum, case-crossover analysis. ${ }^{14} \mathrm{~A}$ case-crossover study can be thought of as a type of self matched case-control study: for each person, exposure data are collected for the "case" day (that is, the day of the myocardial infarction) and a set of "control" days that were not associated with the event of interest. In the fixed stratum design, externally fixed time strata are used as the source of control days, which ensures the validity of standard analytical methods. ${ }^{15}$ In our study, the fixed strata were calendar months and the control days comprised every other day in the calendar month of the myocardial infarction. We obtained data on exposure and confounders relating to the hour of the myocardial infarction event for both case and control days; matching case and control data on time of day in this way avoids confounding due to any natural circadian patterns in risk of myocardial infarction.

We then used conditional logistic regression to compare exposure data on case and control days. The study design automatically controls for time invariant confounders at the individual level, because comparisons are made within patients. For location specific data, including temperature levels, we used the patient's place of residence as the location, so our assumption was that the myocardial infarction occurred in the same conurbation as the patient's home; in $97 \%$ of cases the admitting hospital was in the same conurbation as the patient's residence. We examined the association between ambient temperature and risk of myocardial infarction by using distributed lag models, allowing for delayed effects of up to two weeks. We simultaneously included in our models terms for the following lag periods: 1-6, 7-12, 13-18, 19-24, and 25-48 hours; and 2-7 and 8-14 days. The reason for choosing lag periods of up to two weeks was to cover the total lag period over which we have observed temperature-myocardial infarction associations in a previous analysis at a daily resolution. ${ }^{7} \mathrm{We}$ included finer divisions of time for shorter lag associations to allow for the possibility that fast acting effects may change more rapidly than effects delayed by several days. We initially estimated temperature-myocardial infarction associations by allowing for non-linearity through the use of a natural cubic spline in each lag period. We varied the number of knots defining the spline between one and four, and we chose the value that minimised the Akaike information criterion. To estimate more easily interpretable numerical estimates of the temperature-myocardial infarction association, we then went on to fit models with simpler linear temperature terms and linear threshold temperature terms (which specify that the heat effect operates only above a particular threshold). To estimate the threshold, we fitted the model by using every possible heat threshold in turn (in $1^{\circ} \mathrm{C}$ steps) and chose the threshold giving the highest model likelihood; we also calculated a $95 \%$ confidence interval from the profile likelihood. ${ }^{16}$

All regression models were adjusted for traffic associated pollution, using nitrogen dioxide levels as a marker, ${ }^{9}$ and relative humidity (for both of these variables, we used the same lag structure as for temperature, and we categorised relative humidity in approximate quarters), public holidays, day of the week, and residual seasonality within calendar months (through inclusion of a single harmonic Fourier series with a period of one year $\left.{ }^{17}\right)$.

\section{Effect modifiers and ST elevation versus non-ST elevation myocardial infarctions}

We re-ran our final model separately for ST elevation and non-ST elevation myocardial infarction outcomes, to identify possible differences in the temperature-myocardial infarction associations between these categories of event. We then allowed temperature effects to differ by each of the following individual level factors in turn: age group, sex, previous aspirin use, previous coronary heart disease, previous hypertension, and previous statin use. We used Wald tests on interaction terms to formally test for effect modification by these factors. We excluded any patients with missing data for the effect modifier under consideration.

\section{Post hoc analyses}

After identifying an association between short lag heat and myocardial infarction in our main analysis, we examined more 
closely the pattern over time in this effect, and in particular whether the effect might reflect short term displacement (or "harvesting"), in which myocardial infarction events that would have happened later are simply brought forward by a few hours or days as a result of the environmental trigger. ${ }^{18}$ To explore this, we fitted a model containing $20^{\circ} \mathrm{C}$ threshold temperature lag terms in six hour bands for the full two week lag period (that is, 1-6, 7-12, 13-18, . ., 355-360 hours); we constrained the model such that the estimated effects over lag time followed a smooth curve so as to remove model instability due to collinearities between terms and to enable patterns of effects over time to be drawn out. Specifically, we restricted effects to follow a cubic spline with internal knots at 24, 48, and 192 hours (chosen to correspond to the main analysis and to again reflect the possibility that fast acting effects may change more rapidly than effects delayed by several days). Within this framework, we estimated the independent effect of temperature at each lag, as well as the cumulative effect of temperature over increasing lag periods $(0-6,0-12,0-18,0-24, \ldots, 0-360$ hours $)$, where the cumulative effect of temperature over the lag period 0-24 hours (for example) is the sum of the independent effects at lags 0-6, 7-12, 13-18, and 19-24 hours and can be interpreted as the net effect of a temperature increase "now" on risk of myocardial infarction in the next 24 hours.

We then did a post hoc investigation of possible effect modification by time of day/night (full details and results in web appendix), and we explored the role of immediate versus sustained increases in temperature by examining differences between the estimated heat-myocardial infarction association on the first day of a spell in which temperatures exceeded the heat threshold and the estimated association on days that had been preceded by earlier consecutive days during which temperatures had exceeded the threshold. We achieved this by adding to our final model an interaction between the threshold heat parameter and a binary indicator identifying all days on which the previous day had exceeded the threshold.

\section{Sensitivity analyses}

To assess the robustness of our results to various methodological decisions, we did several sensitivity analyses. Firstly, we restricted our study population to those patients whose time of onset of symptoms of myocardial infarction was directly recorded, rather than inferred from other timing variables. Secondly, we restricted to those patients for whom corroborative evidence (an electrocardiograph trace or creatine kinase/troponin concentrations) supportive of the diagnosis of myocardial infarction was recorded in MINAP. Thirdly, we repeated our main analysis using robust standard errors to account for any possible clustering within conurbations. Fourthly, we restricted to the four largest conurbations (Greater London, Greater Manchester, West Midlands, and West Yorkshire). Fifthly, we used hourly particulate matter with diameter $<10 \mu \mathrm{m}$ and then ozone levels in place of nitrogen oxide to adjust for the potential confounding effects of air pollution. Sixthly, we added adjustment for circulating infectious disease levels (influenza and respiratory syncytial virus). Finally, as a check that any effects of day of the week were fully accounted for, we matched case and control days on day of the week; this also introduced seven day gaps between case and control days and so doubled as a check against any influence of residual autocorrelation on our results.

\section{Results}

A total of 24861 myocardial infarction occurred during the study period and had temperature data available (table $1 \Downarrow$ ), of which 11310 (45\%) were accompanied by ST elevation. Events occurred more commonly among men $(n=16195 ; 65 \%)$ and older people (median age 69 years). Four large conurbations contributed $81 \%$ of the included myocardial infarctions-namely, Greater London (9915; 40\%), Greater Manchester (4112; 17\%), the West Midlands (3546; 14\%), and West Yorkshire $(2608 ; 10 \%)$. Across conurbations, 22768 (92\%) myocardial infarctions had corroborative evidence (electrocardiograph trace or creatine kinase/troponin concentrations) recorded in MINAP that was consistent with the diagnosis.

Time of onset of symptoms was directly recorded for 13541 (54\%) myocardial infarctions, and for the remainder it was inferred from the time of arrival at hospital (9042 events; 36\%) or other time fields ( 2277 events; $9 \%$ ). The distribution of time of myocardial infarction is shown in the web appendix (fig A). Mean daily temperatures across conurbations ranged from $14.3^{\circ} \mathrm{C}$ to $18.4^{\circ} \mathrm{C}$ during the study months (table $2 \Downarrow$ ). At an hourly level, $10 / 11$ conurbations had temperatures above $30^{\circ} \mathrm{C}$ recorded during the study period, and the highest temperature recorded was $36.8^{\circ} \mathrm{C}$ in Greater London on 10 August 2003 during the European heat wave.

We excluded 1413 (6\%) events from our case-crossover analysis owing to missing data on potential confounders (979 with missing pollutant data and a further 434 with missing data on relative humidity).

\section{Short term association between heat and risk of myocardial infarction}

We observed an apparently non-linear association between temperature and myocardial infarction in the shortest lag period of one to six hours; higher temperatures were associated with higher risk at the upper end of the temperature scale, with little association at the lower end $(\mathrm{P}=0.017$ overall; $\mathrm{P}=0.004$ for non-linearity) (fig $1 \Downarrow$ ). At longer lags, we found no evidence of any further association between heat and risk of myocardial infarction; confidence intervals for the estimated curves comfortably included the null ( $\mathrm{P}>0.1$ for each lag term).

In simplified threshold models, the model best supported by the data (on the basis of minimisation of the Akaike information criterion) had a threshold heat effect for one to six hours' lag but simple linear temperature effects at longer lags. We estimated a heat threshold of $20^{\circ} \mathrm{C}(95 \%$ confidence interval $16^{\circ} \mathrm{C}$ to $25^{\circ} \mathrm{C}$ ) for the one to six hour lagged temperature effect (web appendix fig B). Tables $3 \Downarrow$ and $4 \Downarrow$ show estimated effect sizes in the final model. Each $1{ }^{\circ} \mathrm{C}$ increase in temperature above $20^{\circ} \mathrm{C}$ was associated with an estimated $1.9 \%$ (95\% confidence interval $0.5 \%$ to $3.3 \% ; \mathrm{P}=0.009$ ) increase in the risk of myocardial infarction one to six hours after exposure (table $3 \Downarrow$ ), with no evidence of any further heat effect at longer lags.

In a post hoc exploratory model to investigate whether the short lag heat effect might reflect short term displacement of events that would otherwise have happened a little later, we observed that the excess risk at the shortest lags seemed to be followed by a reduced risk around 24 hours after exposure (fig $2 \Downarrow$ ). The cumulative effect of a $1^{\circ} \mathrm{C}$ temperature rise above the threshold was close to zero by the end of the third day after exposure (estimated cumulative risk increase $0.2 \%,-2.1 \%$ to $2.5 \%$ ). 


\section{ST elevation versus non-ST elevation myocardial infarction}

In analyses separating ST elevation and non-ST elevation myocardial infarction outcomes, we observed an indication of a stronger heat-myocardial infarction association for ST elevation myocardial infarction: for each $1^{\circ} \mathrm{C}$ increase in temperature above $20^{\circ} \mathrm{C}$, the risk of ST elevation myocardial infarction was increased by $2.7 \%$ ( $0.6 \%$ to $4.9 \%)$ one to six hours after exposure, compared with an estimated increase in risk of $1.2 \%$ ( $-0.1 \%$ to $3.1 \%$ ) for non-ST elevation myocardial infarction. The point estimate for the association with ST elevation myocardial infarction was contained in the confidence interval for the association between temperature and non-ST elevation myocardial infarction, and vice versa.

\section{Effect modification by individual level factors and by hour of day}

We noted some variation in the point estimates for temperature-myocardial infarction associations by individual level factors, including a larger effect among patients with previous coronary heart disease and those not taking aspirin, and a smaller effect among those with previous hypertension (fig $3 \Downarrow$ ). However, tests of interaction suggested that these observations were consistent with chance variation $(\mathrm{P}>0.2$ in each case). We did not observe any difference in the effect of temperature by time of day ( $\mathrm{P}$ for interaction $=0.58$; web appendix fig C). The lack of evidence for any heat effect applying specifically within the night time stratum $(\mathrm{P}=0.55)$ is consistent with our final threshold model, as the $20^{\circ} \mathrm{C}$ threshold for one to six hour lagged temperature was rarely exceeded in this period.

\section{Immediate versus sustained temperature increases}

We found weak evidence that the short lag temperature-myocardial infarction association was larger on the first day of a hot spell (that is, the first day with hourly temperatures exceeding the $20^{\circ} \mathrm{C}$ threshold; estimated risk increase per $1{ }^{\circ} \mathrm{C}: 6.5 \%, 1.3 \%$ to $11.9 \%$ ) than on days that had followed consecutively from one or more earlier hot days (estimated risk increase per $1^{\circ} \mathrm{C}: 1.7 \%, 0.3 \%$ to $3.2 \%$, P for interaction=0.07). When we further divided subsequent hot days into second to third, fourth to seventh, and eighth or more, we found no difference between these categories $(\mathrm{P}=0.27)$.

\section{Sensitivity analyses}

Our main results were robust to restricting the study population to patients with time of onset of symptoms directly recorded, restricting to those with corroborative evidence supporting the diagnosis of myocardial infarction, using robust standard errors to allow for possible clustering by conurbation, restricting to the four largest conurbations, adjusting for particulate matter with diameter $<10 \mu \mathrm{m}$ or ozone instead of nitrogen dioxide to account for possible confounding by pollution, adjusting for circulating infectious disease levels, and matching case and control days on day of the week (web appendix table A). In each case, the estimated association between higher temperatures (above the threshold level of $20^{\circ} \mathrm{C}$ ) and risk of myocardial infarction one to six hours later was similar to that in the original analysis, with odds ratios ranging from 1.017 to 1.024 per $1{ }^{\circ} \mathrm{C}$ increase, compared with the original estimate of 1.019. Effect estimates at other lags were also similar across sensitivity analyses.

\section{Discussion}

Across 11 conurbations in England and Wales included in our analysis, we observed an association between higher

temperatures and increased risk of myocardial infarction at an hourly temporal resolution. Above a threshold temperature of $20^{\circ} \mathrm{C}\left(95 \%\right.$ confidence interval for estimated threshold $16^{\circ} \mathrm{C}$ to $25^{\circ} \mathrm{C}$ ), each $1^{\circ} \mathrm{C}$ increase in temperature was associated with an estimated $1.9 \%$ ( $95 \%$ confidence interval $0.5 \%$ to $3.3 \%$ ) increase in risk of myocardial infarction in the following one to six hours. We found no evidence of an increase in risk of myocardial infarction at longer lags after exposure to high temperatures, and our results were consistent with a short term displacement or "harvesting" effect of heat, with reductions in risk one to three days after exposure apparently cancelling out the early increase. We believe this to be the first large study to detect apparent temperature related displacement of myocardial infarction events on an hourly timescale.

We found some evidence that the temperature-myocardial infarction association may be larger on the first day of a hot weather period than on subsequent hot days. We did not observe any statistically significant variation in the vulnerability to heat by age, drug use (statins and aspirin), or previous cardiovascular disease.

\section{Comparison with previous studies}

The detrimental effects of heat on overall mortality risk are well established, and threshold heat effects have been observed in several studies. ${ }^{5}{ }^{19}$ Only a few studies specifically looking at associations between temperature and myocardial infarction have been published, and, to our knowledge, no other large study to date has examined changes in risk of myocardial infarction on sub-daily timescales. A recent detailed study of heat effects on cause specific mortality found a smaller signal for mortality due to myocardial infarction than for death from other specific causes, but deaths from myocardial infarction were still estimated to increase by $1.1 \%(0.7 \%$ to $1.5 \%)$ per degree increase above the regional heat threshold. ${ }^{21}$ A systematic review published in 2009 identified 13 earlier studies with relevant data on heat associations with risk of myocardial infarction. ${ }^{6}$ Seven of the 13 studies identified some association with heat, but methodological limitations in many studies were noted, including concerns about potential misclassification of diagnoses of myocardial infarction: the largest effects seemed to be estimated in studies in which cases of myocardial infarction were identified only on the basis of mortality and cause of death data, which could have been subject to miscoding. Only one of the five studies with separately validated myocardial infarction outcomes detected a heat effect. ${ }^{22}$ Correspondingly, a more recent systematic review and meta-analysis considering a range of cardiorespiratory effects of temperature changes found little evidence for an association between heat and myocardial infarction. ${ }^{23}$ In our recent large scale investigation of temperature-myocardial infarction associations using year round data, we observed an increased risk of myocardial infarction at lower temperatures, but no heat effect. ${ }^{7}$ However, this study, in common with all those identified in the aforementioned systematic reviews and a recent German study, ${ }^{24}$ was conducted on a daily timescale; the results of the analysis presented here suggest a raised risk of myocardial infarction in the few hours after a temperature increase that may be largely offset by reductions in risk just a day or so later, consistent with short term displacement, and this may explain the lack of a consistently detected heat signal in previous studies that have used only daily data. 
We did not observe any statistically significant effect modification by individual level factors. The lack of apparent effect modification by age in our study is in contrast to evidence that elderly people are more vulnerable than other age groups to associations between heat and mortality more broadly. ${ }^{25}$ Our results suggest that this excess vulnerability may not be driven by risk of myocardial infarction specifically, although our analysis may have been underpowered to detect relatively subtle effect modification. In recent data from Australia, districts with larger elderly populations had the largest increases in admissions for myocardial infarction on hot days, which would support increased vulnerability among elderly people, although other differences between districts could explain the observation. ${ }^{26}$

\section{Public health implications and possible mechanisms}

The short lag heat effect we observed was consistent with short term displacement of events rather than a net addition to the burden of myocardial infarctions. Several studies of broader mortality outcomes have similarly concluded that detrimental heat related increases in risk may be largely explained by a short term displacement phenomenon, ${ }^{18}{ }^{27}$ although others have estimated some net effect, at least in selected locations. ${ }^{19}{ }^{20}$ Our findings indicate that overall incidence of myocardial infarction may not be affected by policies aimed at reducing or managing exposure to heat. Nevertheless, important clustering of events around times of high temperatures may occur. The overall estimated $1.9 \%$ relative increase in risk of myocardial infarction over a six hour period per $1^{\circ} \mathrm{C}$ increase in temperature may translate to detectable and potentially important changes in the temporal distribution of events at certain times for several reasons. Firstly, myocardial infarctions are common and exposure to temperature can be considered universal, so small percentage increases can translate to substantial absolute increases. Secondly, we estimated considerably larger risk increases associated with temperature on the first day of a hot spell (6.5\% per $1{ }^{\circ} \mathrm{C}$ above threshold), compared with the overall effect, and this may be just the time that the relevant services are less ready for any weather related adverse health effects. Thirdly, temperatures may increase by considerably more than $1^{\circ} \mathrm{C}$ at the start of a hot period, leading to a potentially important temporal displacement of events. A strong evidence base shows that the rapid initiation of intensive treatment for acute myocardial infarction has a direct effect on survival, as a result of which the personnel and resources diverted to dealing with each individual acute myocardial infarction are considerable. ${ }^{28}$ Therefore, for acute sector health services, the increases described above may present a substantial and important challenge. Strategies aimed at avoiding the early triggering of events that we have described might therefore improve ultimate outcomes by reducing the resultant stresses on the emergency and hospital services. One such strategy might involve the wider use of systems to disseminate public health advice on clothing, hydration, and physical activity at times when a new spell of hot weather is forecast. England implemented a heat wave plan after the 2003 European heat wave, but the current plan activates only when forecasts indicate the possibility of sustained temperatures above $28-32^{\circ} \mathrm{C}$ (depending on region), and it has been triggered only a handful of times in eight years of operation. ${ }^{29}$ Our results, in line with studies of broader outcomes, suggest that myocardial infarctions may be triggered at considerably lower temperatures, and we observed a larger heat-myocardial infarction association on the first day of a hot spell than after sustained high temperatures.
Possible mechanisms for heat effects triggering thrombotic events have not been widely studied. The diversion of blood flow at high temperatures away from the vital organs and to dilated vessels near the skin surface for cooling may increase cardiac strain. ${ }^{30}{ }^{31}$ Haemoconcentration and increased blood viscosity through loss of fluid may also contribute, ${ }^{31}$ and changes in cholesterol concentrations and sweating threshold have also been implicated. ${ }^{32}{ }^{33}$ Keatinge et al published experimental evidence based on human volunteers exposed to moving air at $41{ }^{\circ} \mathrm{C}$ for six hours, the same timescale over which we observed an increase in risk of myocardial infarction in this study: the authors observed weight losses with sweating, despite ready access to water, and losses of arterial pressure; red blood cell count, platelet count, and blood viscosity all increased. ${ }^{34}$ However, these data were published more than two decades ago, and recent data using an updated range of measures including haemostatic factors are lacking.

One must also consider whether our findings could simply reflect chance variation. In our final model, we estimated the effect of temperature by using seven lag terms; for a family-wise significance level of 5\%, a simple (Bonferroni) correction for multiple testing would require $\mathrm{P}<0.007$ as evidence of an effect at an individual lag. We did not formally apply the correction as, for non-independent outcomes, it would probably be over-conservative ${ }^{35}$ nevertheless, the short lag effect we identified (with corresponding $\mathrm{P}=0.009$ ) should be considered in the light of this multiple testing, and we would interpret the $P$ value as representing strong but not overwhelming evidence of a true effect. Further studies using hourly data to confirm and further characterise the effects we have observed would therefore be welcome.

\section{Strengths and limitations}

Our study has several limitations. Firstly, the MINAP database records myocardial infarctions in patients who were admitted to hospital, but events resulting in death before admission would have been missed. The likelihood of surviving a myocardial infarction could plausibly be related to temperature-for example, if myocardial infarctions triggered by heat tend to be more severe or if clustering of adverse health outcomes on hot days causes delays in emergency services. Any resulting bias would be likely to be in the direction of an underestimation of heat related myocardial infarctions, and so of the heat-myocardial infarction association.

Secondly, our analysis was based on data on the time of onset of symptoms, but symptom onset may describe different clinical stages for different people; symptoms of myocardial infarction may begin with varying chest pain over several hours, and patients' self reported time of symptom onset may be influenced by factors such as when their doctor was reachable on the phone. These factors would effectively have led to measurement error in capturing the true time of onset of symptoms, and the result is likely to have been a bias in our results towards the null. Furthermore, time of symptom onset was not directly recorded for a proportion of patients but inferred from other variables such as time of admission, although our results seemed to be robust to restriction to patients with time of symptom onset directly recorded.

Thirdly, residual confounding may be present in our results. The key candidate confounder is air pollution levels, which have been shown to be associated with risk of myocardial infarction on this timescale. ${ }^{9}$ In our primary analysis, we adjusted for hourly levels of nitrogen dioxide, the pollutant with the strongest association with myocardial infarction in our previous study, 
and our results were similar in sensitivity analyses using ozone and particulate matter with diameter $<10 \mu \mathrm{m}$ as alternative pollution markers. We did not have data on fine particle levels $(<2.5 \mu \mathrm{m})$, which may be a more important predictor of risk of myocardial infarction than particulate matter with diameter $<10$ $\mu \mathrm{m},{ }^{36}$ but in one station recording both we observed a high correlation between the measures (0.92) suggesting that adjustment for particulate matter with diameter $<10 \mu \mathrm{m}$ should have accounted for any major confounding effects of finer particles.

Finally, our data did not include potentially important individual level data, such as time spent outdoors (or activity levels, which could act as a proxy), characteristics of housing, and air conditioning, which may modify individual people's vulnerability to any heat effects (although residential air conditioning remains relatively uncommon in the UK).

Despite these limitations, to our knowledge, this is the largest study to date to investigate associations between heat and risk of myocardial infarction by using data at an hourly temporal resolution. The case-crossover design that we used automatically controls for time invariant individual level factors, we matched on hour of onset to control for confounding by time of day, and we were able to adjust for other key confounders including hourly pollution levels, day of the week effects, and (in a sensitivity analysis) circulating infectious disease levels (influenza, respiratory syncytial virus). Several studies investigating the associations between temperature and risk of myocardial infarction have relied on mortality data or unvalidated diagnoses, and both of these strategies may reduce the specificity of the outcome; in this study, more than $90 \%$ of diagnoses of myocardial infarction were backed up within MINAP by corroborative electrocardiographic or laboratory marker evidence, and our results were similar when we restricted analysis to cases with such evidence. Finally, MINAP has comprehensive coverage and does not restrict on demographic criteria, so hospital admissions recorded should be representative of those occurring within the locations under study.

\section{Conclusion}

In 11 large conurbations in England and Wales, short term risk of myocardial infarction seemed to increase at higher temperatures, above a threshold of $20^{\circ} \mathrm{C}$. The increase in risk was observed just one to six hours after exposure and seemed to be offset by a reduction in risk in the following days, consistent with exposure to heat leading to an early triggering of myocardial infarctions in highly vulnerable people who would otherwise have had a myocardial infarction some time later ("short term displacement"). This suggests that the overall incidence of myocardial infarction may not be affected by policies aimed at reducing or managing exposure to heat, but important clustering of events may occur during hot spells, potentially leading to high demands on the relevant health services and worse outcomes of myocardial infarction. Further work using hourly data is needed to quantify the extent of any such clustering on an absolute scale and to further characterise short term heat-myocardial infarction associations. Future studies might also clarify whether local climate modifies these associations; assess the importance of indoor temperatures, characteristics of housing, and air conditioning; and investigate possible biological mechanisms for heat associated triggering of myocardial infarctions by using a range of updated markers. Policies aimed at reducing the health effects of hot weather and heat waves should include a consideration of effects operating on sub-daily timescales.
Contributors: All authors were involved in the design of the study. KB prepared and cleaned the data, did the statistical analysis, and wrote the first draft. All authors contributed to further drafts. KB is the guarantor.

Funding: This work was supported by the British Heart Foundation (grant number FS/04/045), the Wellcome Trust (grant number 086091/Z/08/Z), and the Garfield Weston Foundation. KB is supported by a National Institute for Health Research postdoctoral fellowship (grant number NIHR-PDF-2011-04-007). LS is supported by a Wellcome Trust senior research fellowship in clinical science (grant number 098504/Z/12/Z). The British Heart Foundation, the Garfield Weston Foundation, the National Institute for Health Research, and the Wellcome Trust had no role in the design or conduct of this study, or in the preparation, review, approval, or decision to submit the manuscript. All authors carried out this research independently of the funding bodies.

Competing interests: All authors have completed ICMJE uniform disclosure form at www.icmje.org/coi_disclosure.pdf (available on request from the corresponding author) and declare: support for the work came from the British Heart Foundation, the Garfield Weston Foundation, the National Institute for Health Research, and the Wellcome Trust; no financial relationships with any organisations that might have an interest in the submitted work in the previous three years; no other relationships or activities that could appear to have influenced the submitted work.

Ethical approval: Ethics approval for the study was granted by the London School of Hygiene and Tropical Medicine Ethics Committee (application number 5218)

Data sharing: No additional data available.

1 Semenza JC, Rubin CH, Falter KH, Selanikio JD, Flanders WD, Howe HL, et al. Heat-related deaths during the July 1995 heat wave in Chicago. N Engl J Med 1996;335:84-90.

2 Kunst AE, Looman CW, Mackenbach JP. Outdoor air temperature and mortality in the Netherlands: a time-series analysis. Am J Epidemiol 1993;137:331-41.

3 Goldberg MS, Gasparrini A, Armstrong B, Valois MF. The short-term influence of temperature on daily mortality in the temperate climate of Montreal, Canada. Environ Res 2011;111:853-60.

4 Curriero FC, Samet JM, Zeger SL. Re: "On the use of generalized additive models in time-series studies of air pollution and health" and "Temperature and mortality in 11 cities of the eastern United States". Am J Epidemiol 2003;158:93-4.

5 Curriero FC, Heiner KS, Samet JM, Zeger SL, Strug L, Patz JA. Temperature and mortality in 11 cities of the eastern United States. Am J Epidemiol 2002;155:80-7.

6 Bhaskaran K, Hajat S, Haines A, Herrett E, Wilkinson P, Smeeth L. Effects of ambient temperature on the incidence of myocardial infarction. Heart 2009:95:1760-9.

7 Bhaskaran K, Hajat S, Haines A, Herrett E, Wilkinson P, Smeeth L. Short term effects of temperature on risk of myocardial infarction in England and Wales: time series regression analysis of the Myocardial Ischaemia National Audit Project (MINAP) registry. BMJ 2010;341:c3823.

8 Yu W, Hu W, Mengersen K, Guo Y, Pan X, Connell D, et al. Time course of temperature effects on cardiovascular mortality in Brisbane, Australia. Heart 2011:97:1089-93.

9 Bhaskaran K, Hajat S, Armstrong B, Haines A, Herrett E, Wilkinson P, et al. The effects of hourly differences in air pollution on the risk of myocardial infarction: case crossover analysis of the MINAP database. BMJ 2011;343:d5531.

10 Mills NL, Tornqvist H, Gonzalez MC, Vink E, Robinson SD, Derberg S, et al. Ischemic and thrombotic effects of dilute diesel-exhaust inhalation in men with coronary heart disease. N Engl J Med 2007:357:1075-82.

11 Doherty RM, Hearl MR, Wilkinson P, Pattenden S, Vieno M, Armstrong B, et al. Current and future climate- and air pollution-mediated impacts on human health. Environ Health 2009;8(suppl 1):S8.

12 UK Meteorological Office. Met Office Integrated Data Archive System (MIDAS) land and marine surface stations data (1853-current). 2012. http://badc.nerc.ac.uk/view/badc.nerc. ac.uk ATOM dataent ukmo-midas.

13 Department for Environment, Food and Rural Affairs. UK-AIR data archive. 2011. http:// uk-air.defra.gov.uk/data/.

14 Lumley T, Levy D. Bias in the case-crossover design: implications for studies of ai pollution. Environmetrics 2000;11:689-704.

15 Janes H, Sheppard L, Lumley T. Case-crossover analyses of air pollution exposure data: referent selection strategies and their implications for bias. Epidemiology 2005;16:717-26

16 Stryhn H, Christensen J. Confidence intervals by the profile likelihood method, with applications in veterinary epidemiology [abstract]. International Symposia on Veterinary Epidemiology and Economics (ISVEE), Vina del Mar, Chile, 2003.

17 Woolhiser DA, Pegram GGS. Maximum likelihood estimation of Fourier coefficients to describe seasonal variation of parameters in stochastic daily precipitation models. Journal of Applied Meteorology 1979;18:34-42.

18 Schwartz J, Samet JM, Patz JA. Hospital admissions for heart disease: the effects of temperature and humidity. Epidemiology 2004;15:755-61.

19 Baccini M, Biggeri A, Accetta G, Kosatsky T, Katsouyanni K, Analitis A, et al. Heat effects on mortality in 15 European cities. Epidemiology 2008;19:711-9.

20 Hajat S, Armstrong BG, Gouveia N, Wilkinson P. Mortality displacement of heat-related deaths: a comparison of Delhi, Sao Paulo, and London. Epidemiology 2005;16:613-20. 


\section{What is already known on this topic}

High ambient temperatures are associated with increased overall short term mortality

Whether high temperatures are linked to an increased risk specifically of myocardial infarction is unclear

Most previous studies have compared changes in temperature with changes in risk of myocardial infarction by using data at a daily temporal resolution; few data at sub-daily timescales have been available

\section{What this study adds}

Data at an hourly temporal resolution from 11 conurbations in England and Wales showed higher temperatures to be associated with increased risk of myocardial infarction in the six hours after exposure, above a threshold of $20^{\circ} \mathrm{C}$

Subsequent reductions in risk one to three days after exposure suggested that myocardial infarction may have been triggered early in highly vulnerable people who would otherwise have had an event shortly afterwards

Policies aimed at reducing the health effects of hot weather and heat waves need to consider effects operating on sub-daily timescales

21 Gasparrini A, Armstrong B, Kovats S, Wilkinson P. The effect of high temperatures on cause-specific mortality in England and Wales. Occup Environ Med 2012;69:56-61.

22 Messner T, Lundberg V, Wikstrom B. A temperature rise is associated with an increase in the number of acute myocardial infarctions in the subarctic area. Int $J$ Circumpolar Health 2002;61:201-7.

23 Turner LR, Barnett AG, Connell D, Tong SL. Ambient temperature and cardiorespiratory morbidity: a systematic review and meta-analysis. Epidemiology 2012;23:594-606.

24 Wolf K, Schneider A, Breitner S, von Klot S, Meisinger C, Cyrys J, et al. Air temperature and the occurrence of myocardial infarction in Augsburg, Germany. Circulation 2009; 120:735-42.

25 Hajat S, Kovats RS, Lachowycz K. Heat-related and cold-related deaths in England and Wales: who is at risk? Occup Environ Med 2007;64:93-100.

26 Loughnan ME, Nicholls N, Tapper NJ. The effects of summer temperature, age and socioeconomic circumstance on acute myocardial infarction admissions in Melbourne, Australia. Int J Health Geogr 2010;9:41.

27 Braga AL, Zanobetti A, Schwartz J. The time course of weather-related deaths. Epidemiology 2001;12:662-7.

28 Steg PG, James SK, Atar D, Badano LP, Lundqvist CB, Borger MA, et al. ESC guidelines for the management of acute myocardial infarction in patients presenting with ST-segmen elevation: the Task Force on the management of ST-segment elevation acute myocardial infarction of the European Society of Cardiology (ESC). Eur Heart J 2012;33):2569-619.

29 Department of Health. Heatwave plan for England: protecting health and reducing harm from extreme heat and heatwaves. 2011. www.dh.gov.uk/en/Publicationsandstatistics/ Publications/PublicationsPolicyAndGuidance/DH_126666.

30 Basu R. High ambient temperature and mortality: a review of epidemiologic studies from 2001 to 2008. Environ Health 2009;8:40.
31 Nayha S. Environmental temperature and mortality. Int J Circumpolar Health 2005;64:451-8.

32 Astrand P, Rodahl K, Dahl HA, Stromme SB. Textbook of work physiology: physiological bases of exercise. 4th ed. McGraw-Hill, 2003.

33 Halonen JI, Zanobetti A, Sparrow D, Vokonas PS, Schwartz J. Outdoor temperature is associated with serum HDL and LDL. Environ Res 2011;111:281-7.

34 Keatinge WR, Coleshaw SR, Easton JC, Cotter F, Mattock MB, Chelliah R. Increased platelet and red cell counts, blood viscosity, and plasma cholesterol levels during heat stress, and mortality from coronary and cerebral thrombosis. Am J Med 1986;81:795-800.

35 Bland JM, Altman DG. Multiple significance tests: the Bonferroni method. BMJ 1995;310:170.

36 Bhaskaran K, Hajat S, Haines A, Herrett E, Wilkinson P, Smeeth L. Effects of air pollution on the incidence of myocardial infarction. Heart 2009;95:1746-59.

Accepted: 11 November 2012

\section{Cite this as: BMJ 2012;345:e8050}

This is an open-access article distributed under the terms of the Creative Commons Attribution Non-commercial License, which permits use, distribution, and reproduction in any medium, provided the original work is properly cited, the use is non commercial and is otherwise in compliance with the license. See: http://creativecommons.org/licenses/bync/2.0/ and http://creativecommons.org/licenses/by-nc/2.0/legalcode. 


\section{Tables}

Table 1 | Characteristics of myocardial infarctions occurring within 11 conurbations over period 2003-09 inclusive (months of June-August inclusive). Values are numbers ${ }^{\star}$ (percentages) unless stated otherwise

\begin{tabular}{|c|c|c|c|c|c|c|c|c|}
\hline Conurbation & $\begin{array}{l}\text { Myocardial } \\
\text { infarctions }\end{array}$ & $\begin{array}{l}\text { Corroborative } \\
\text { evidence } †\end{array}$ & ST elevation & $\begin{array}{l}\text { Median (range) } \\
\text { age (years) }\end{array}$ & Male sex & Previous CHD & Taking aspirin & Taking statin \\
\hline Bristol & 737 & 707/737 (96) & $394 / 737(53)$ & $69(30-100)$ & $487 / 737(66)$ & $219 / 670$ (33) & $219 / 720(30)$ & $116 / 381(30)$ \\
\hline Cardiff & 263 & 259/263 (98) & 98/263 (37) & $75(41-96)$ & 153/263 (58) & $82 / 210(39)$ & $108 / 258(42)$ & 28/88 (32) \\
\hline Greater London & 9915 & $8879 / 9915(90)$ & $4302 / 9915(43)$ & $68(20-107)$ & $6590 / 9915(66)$ & $3011 / 8883(34)$ & $2129 / 9458(23)$ & $2681 / 6502(41)$ \\
\hline $\begin{array}{l}\text { Greater } \\
\text { Manchester }\end{array}$ & 4112 & $3743 / 4112(91)$ & $1751 / 4112(43)$ & $70(21-100)$ & $2631 / 4112(64)$ & $1248 / 2948(42)$ & $625 / 3946(16)$ & 948/2292 (41) \\
\hline Liverpool & 1417 & $1274 / 1417(90)$ & $593 / 1417(42)$ & $71(24-101)$ & $847 / 1417(60)$ & $432 / 1144(38)$ & $117 / 1383$ ( 8 ) & $570 / 940(61)$ \\
\hline Nottingham & 416 & $402 / 416(97)$ & $276 / 416(66)$ & 67 (29-95) & $289 / 416(69)$ & $106 / 317(33)$ & $55 / 406(14)$ & $118 / 201(59)$ \\
\hline Potteries & 296 & 292/296 (99) & $152 / 296(51)$ & $69(35-96)$ & $186 / 296(63)$ & 79/295 (27) & $56 / 296(19)$ & $81 / 261(31)$ \\
\hline Sheffield & 682 & $651 / 682(95)$ & $281 / 682(41)$ & $70(20-99)$ & $417 / 682(61)$ & $189 / 541(35)$ & $26 / 583(4)$ & $26 / 85(31)$ \\
\hline Tyneside & 869 & $698 / 869(80)$ & $319 / 869$ (37) & $71(22-96)$ & $500 / 869(58)$ & $227 / 571(40)$ & $221 / 845(26)$ & $44 / 78(56)$ \\
\hline West Midlands & 3546 & $3412 / 3546(96)$ & $1896 / 3546(53)$ & $68(24-104)$ & $2419 / 3546(68)$ & $792 / 2483(32)$ & $354 / 3422(10)$ & $607 / 1705(36)$ \\
\hline West Yorkshire & 2608 & $2451 / 2608$ (94) & $1248 / 2608(48)$ & 67 (23-99) & $1676 / 2608(64)$ & $898 / 2401$ (37) & $547 / 2435(22)$ & $952 / 1720(55)$ \\
\hline Total & 24861 & 22 768/24 861 (92) & $\begin{array}{c}11310 / 24861 \\
(45)\end{array}$ & $69(20-107)$ & $\begin{array}{c}16 \text { 195/24 } 861 \\
(65)\end{array}$ & $7283 / 20463$ (36) & $4457 / 23752(19)$ & $6171 / 14253(43)$ \\
\hline
\end{tabular}

$\mathrm{CHD}=$ coronary heart disease.

*Denominators reflect number of people with non-missing data for specified variable.

†Defined for ST elevation myocardial infarction as an electrocardiograph or marker concentrations (troponin or creatine kinase) consistent with diagnosis, and for non-ST elevation myocardial infarction as marker concentrations consistent with diagnosis. 


\begin{tabular}{|c|c|c|c|c|c|}
\hline \multirow[b]{2}{*}{ Conurbation } & \multirow[b]{2}{*}{ No of years with hourly data available } & \multicolumn{4}{|c|}{ Mean (hourly range) daily temperature $\left({ }^{\circ} \mathrm{C}\right)$} \\
\hline & & June & July & August & Overall \\
\hline Bristol & 7 & $16.1(5.8-29.8)$ & $17.3(8.7-34.5)$ & $17.2(6.9-31.9)$ & $16.9(5.8-34.5)$ \\
\hline Cardiff & 3 & $16.7(7.0-29.1)$ & $17.6(9.7-32.0)$ & $18.4(7.5-31.5)$ & $17.5(7.0-32.0)$ \\
\hline Greater London & 7 & $16.8(6.0-31.7)$ & $18.3(9.6-33.9)$ & $18.1(8.6-36.8)$ & $17.8(6.0-36.8)$ \\
\hline Greater Manchester & 7 & $15.7(4.9-28.3)$ & $17.0(8.1-31.2)$ & $16.8(5.6-31.8)$ & $16.5(4.9-31.8)$ \\
\hline Liverpool & 7 & $15.2(4.3-28.6)$ & $16.9(7.9-33.8)$ & $16.7(3.7-32.6)$ & $16.3(3.7-33.8)$ \\
\hline Nottingham & 7 & $15.1(4.1-30.0)$ & $16.6(7.0-30.6)$ & $16.5(7.3-31.8)$ & $16.1(4.1-31.8)$ \\
\hline Potteries & 2 & $14.3(5.4-26.3)$ & $16.0(7.0-31.0)$ & $15.2(7.5-25.8)$ & $15.2(5.4-31.0)$ \\
\hline Sheffield & 4 & $15.4(2.8-28.9)$ & $16.5(8.6-29.5)$ & $17.0(5.2-31.2)$ & $16.3(2.8-31.2)$ \\
\hline Tyneside & 3 & $15.0(5.3-27.6)$ & $15.9(9.9-27.0)$ & $16.1(8.1-26.2)$ & $15.7(5.3-27.6)$ \\
\hline West Midlands & 7 & $15.2(3.7-30.1)$ & $16.6(7.6-33.7)$ & $16.5(6.5-33.3)$ & $16.1(3.7-33.7)$ \\
\hline West Yorkshire & 6 & $14.8(3.4-29.6)$ & $16.3(8.2-31.7)$ & $16.2(7.4-30.0)$ & $15.8(3.4-31.7)$ \\
\hline
\end{tabular}


Table 3 | Odds ratios $(95 \% \mathrm{Cl}$ ) for myocardial infarction associated with temperature and potential confounders in final model—distributed lag effects*

\begin{tabular}{|c|c|c|c|c|c|c|c|}
\hline \multirow{2}{*}{$\begin{array}{l}\text { Potential } \\
\text { confounders }\end{array}$} & \multicolumn{7}{|c|}{ Lag (hours) } \\
\hline & $1-6$ & $7-12$ & $13-18$ & $19-24$ & $25-48$ & $49-192$ & $193-360$ \\
\hline $\begin{array}{l}\text { Temperature (per } \\
{ }^{\circ} \mathrm{C} \text { ) }\end{array}$ & $\begin{array}{c}1.019+(1.005 \text { to } \\
1.033)\end{array}$ & $\begin{array}{c}1.002(0.991 \text { to } \\
1.014)\end{array}$ & $\begin{array}{c}1.011(0.997 \text { to } \\
1.026)\end{array}$ & $\begin{array}{c}0.989(0.977 \text { to } \\
1.001)\end{array}$ & $\begin{array}{c}0.991 \text { ( } 0.981 \text { to } \\
1.001)\end{array}$ & $\begin{array}{c}0.996(0.986 \text { to } \\
1.006)\end{array}$ & $\begin{array}{c}0.991 \text { (0.981 to } \\
1.002)\end{array}$ \\
\hline$P$ value & 0.009 & 0.677 & 0.124 & 0.074 & 0.074 & 0.401 & 0.101 \\
\hline \multicolumn{8}{|l|}{$\begin{array}{l}\text { Relative humidity } \\
(\%) \text { : }\end{array}$} \\
\hline$<70$ & 1 (reference) & 1 (reference) & 1 (reference) & 1 (reference) & 1 (reference) & 1 (reference) & 1 (reference) \\
\hline $70-79$ & 0.97 (0.93 to 1.02$)$ & 1.03 (0.99 to 1.08$)$ & 1.05 (1.00 to 1.09$)$ & 0.95 (0.91 to 1.00$)$ & $1.01(0.97$ to 1.04$)$ & $1.00(0.96$ to 1.04$)$ & $0.98(0.94$ to 1.02$)$ \\
\hline $80-89$ & $0.99(0.94$ to 1.04$)$ & 1.06 (1.01 to 1.12$)$ & $1.04(0.98$ to 1.10$)$ & $0.95(0.90$ to 1.00$)$ & $1.00(0.96$ to 1.04$)$ & $1.02(0.96$ to 1.08$)$ & $1.00(0.95$ to 1.06$)$ \\
\hline $90-100$ & $0.94(0.89$ to 1.00$)$ & $1.03(0.96$ to 1.11$)$ & $1.06(0.99$ to 1.15$)$ & $0.96(0.90$ to 1.03$)$ & 0.94 (0.88 to 1.02$)$ & $0.94(0.83$ to 1.07$)$ & $1.01(0.88$ to 1.16$)$ \\
\hline$P$ value & 0.186 & 0.089 & 0.209 & 0.107 & 0.329 & 0.517 & 0.592 \\
\hline $\begin{array}{l}\text { Nitrogen dioxide } \\
\left(\text { per } 10 \mu \mathrm{g} / \mathrm{m}^{3}\right)\end{array}$ & $\begin{array}{c}0.997 \text { (0.981 to } \\
1.014)\end{array}$ & $\begin{array}{c}1.000(0.981 \text { to } \\
1.020)\end{array}$ & $\begin{array}{c}0.990(0.970 \text { to } \\
1.010)\end{array}$ & $\begin{array}{c}1.016(0.997 \text { to } \\
1.035)\end{array}$ & $\begin{array}{c}0.987(0.967 \text { to } \\
1.006)\end{array}$ & $\begin{array}{c}0.994(0.963 \text { to } \\
1.025)\end{array}$ & $\begin{array}{c}1.009(0.977 \text { to } \\
1.043)\end{array}$ \\
\hline$P$ values & 0.763 & 0.997 & 0.314 & 0.110 & 0.179 & 0.698 & 0.575 \\
\hline
\end{tabular}


Table 4 | Odds ratios for myocardial infarction associated with temperature and potential confounders in the final model-fixed/single lag effects*

Potential confounders

Odds ratio $(95 \% \mathrm{Cl}) \mathrm{P}$ value

Holiday

$0.97(0.85$ to 1.11$) \quad 0.701$

Day of week:

1 (reference) $<0.001$

\begin{tabular}{lr} 
Sunday & $<0.001$ \\
\hline Monday & $1.17(1.11$ to 1.23$)$ \\
\hline Tuesday & $1.06(1.00$ to 1.11$)$ \\
\hline Wednesday & $1.07(1.02$ to 1.13$)$ \\
\hline Thursday & $1.05(0.99$ to 1.10$)$ \\
\hline Friday & $1.08(1.03$ to 1.14$)$ \\
\hline Saturday & $0.99(0.94$ to 1.04$)$ \\
\hline
\end{tabular}

*All lag terms were included in model simultaneously; model also adjusted for residual seasonality within calendar months by using single harmonic Fourier series. ${ }^{17}$ 


\section{Figures}
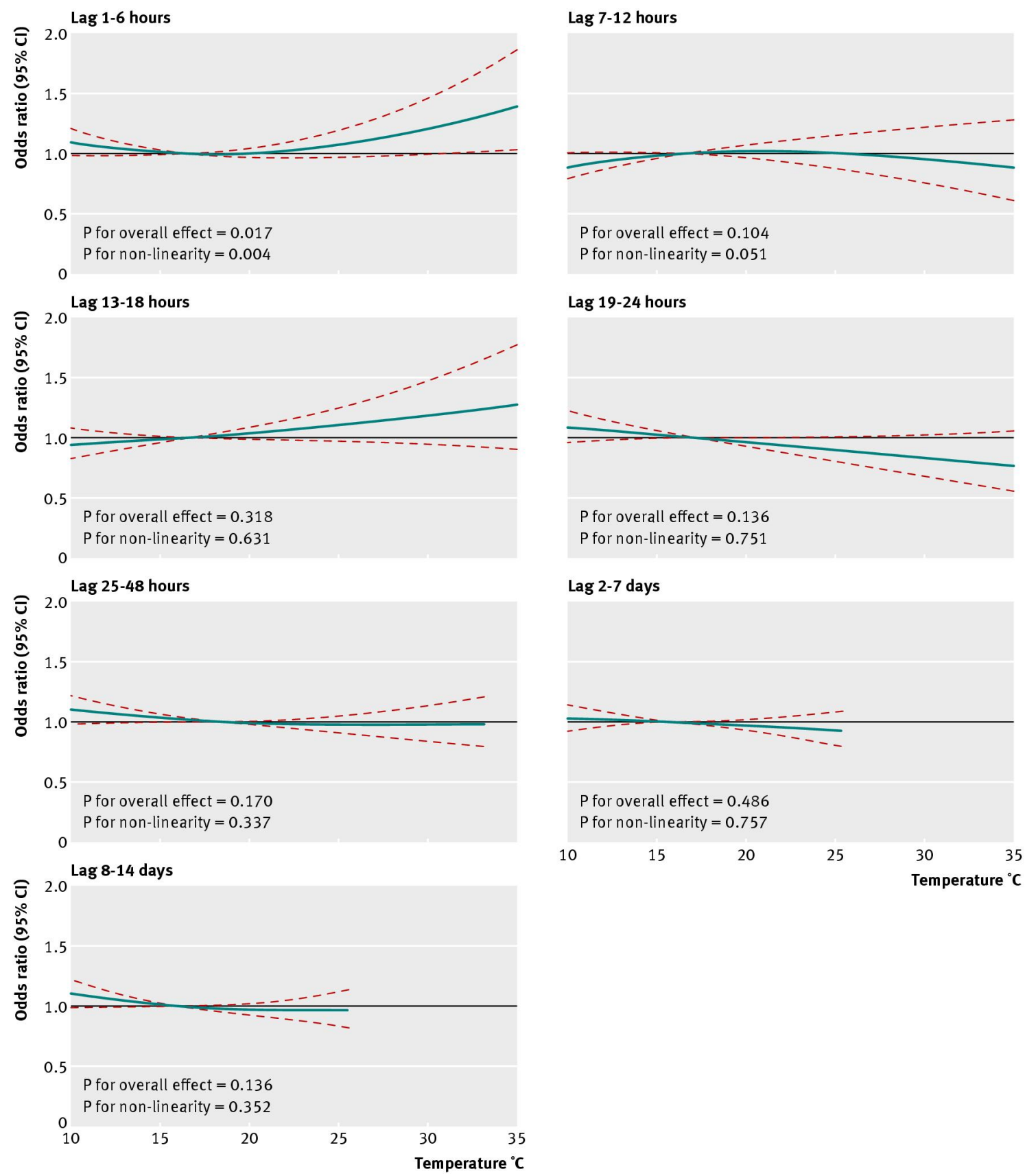

Fig 1 Odds ratio for risk of myocardial infarction by temperature at various lag times from 1 hour to 14 days. Splines have a single interior knot; up to 4 interior knots per spline were allowed, but lowest Akaike information criterion value was obtained with 1 interior knot per spline. Reference temperature (odds ratio=1) is at mean temperature for each lag period; model includes spline bases for all lag periods simultaneously and was adjusted for relative humidity, nitrogen dioxide, holiday, day of week, and residual seasonality within calendar months (using single harmonic Fourier series ${ }^{17}$ ) 

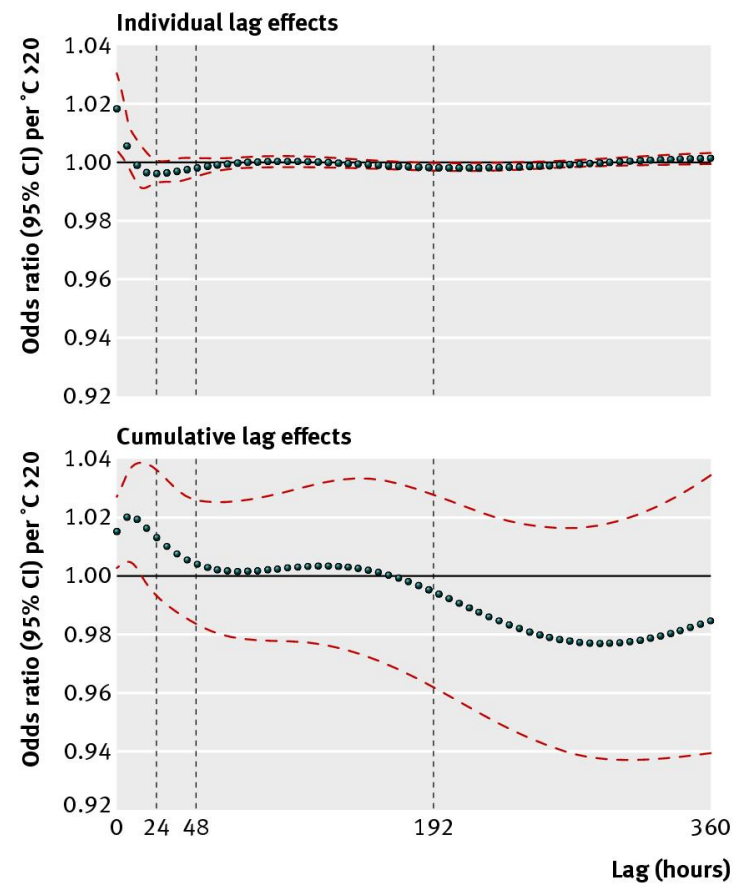

Fig 2 Estimated temperature-myocardial infarction association by lag. Individual lag effects represent estimated independent associations between temperature and risk of myocardial infarction for each lag period (0-6, 7-12, 13-18, . ., 355-360 hours); cumulative lag effects represent the estimated cumulative associations between temperature and myocardial infarction over increasing lag periods $(0-6,0-12,0-18, \ldots, 0-360$ hours) and were calculated as sum of independent effects at individual lags up to that point (for example, cumulative effect over lag period 0-24 hours is sum of independent effects at lags $0-6,7-12,13-18$, and 19-24 hours). Model included temperature in 6 hourly lag bands covering full 2 week lag period $(1-6,7-12, \ldots, 355-360$ hours) with coefficients restricted to follow cubic spline by lag time, having interior knots at 24, 48, and 192 lag hours. Temperature threshold of $20^{\circ} \mathrm{C}$ was applied at all lags. Marked points indicate estimated effect for each 6 hour lag period. Model adjusted for relative humidity, nitrogen dioxide, holiday, day of week, and residual seasonality within calendar months (using single harmonic Fourier series ${ }^{17}$ ) 
Age group

$<60$

$60-69$

70-79

$\geq 80$

Sex

Women

Men

Receiving aspirin

No

Yes

Prior coronary heart disease 0.212

No

Yes

Prior hypertension

No

Yes

Receiving statin

No

Yes

Odds ratio $(95 \% \mathrm{Cl})$ for

(interaction) myocardial infarction

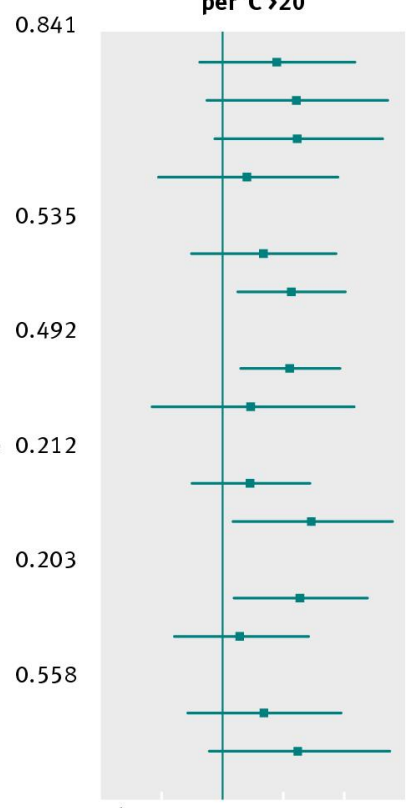

$0.960 .98 \quad 1.001 .02 \quad 1.041 .06$

Fig 3 Potential effect modifiers for short term heat effect. Each potential effect modifier was investigated in separate model, containing interaction between lag 1-6 hour temperature term (with threshold of $20^{\circ} \mathrm{C}$ applied) and variable of interest. All models were adjusted for longer lag periods (linear terms), relative humidity, nitrogen dioxide, holiday, day of week, and residual seasonality within calendar months (using single harmonic Fourier series ${ }^{17}$ ). Numbers of cases in each stratum were as follows: age—group <60 ( $n=6855), 60-69$ (5184), 70-79 (6040), $\geq 80$ (5241), missing (128); sex-female (8006), male (15276), missing (166); receiving aspirin—no (18 227), yes (4161), missing (1060); prior coronary heart disease-no (12 423), yes (6882), missing (4143); prior hypertension-no (9406), yes (9946), missing (4096); receiving statin-no (7625), yes (5782), missing (10 041) 